\title{
Long-term trends in the incidence and relative survival of colorectal cancer in Canada: A population-based study
}

\author{
Noori Akhtar-Danesh*1,3, Gileh-Gol Akhtar-Danesh ${ }^{3}$, Paul Moayyedi ${ }^{2,4}$ \\ ${ }^{1}$ School of Nursing, McMaster University, Hamilton, Canada \\ ${ }^{2}$ Department of Clinical Epidemiology \& Biostatistics, McMaster University, Hamilton, Canada \\ ${ }^{3}$ School of Medicine, McMaster University, Hamilton, Canada \\ ${ }^{4}$ Division of Gastroenterology, Department of Medicine, McMaster University, Hamilton, Canada
}

Received: April 9, 2016

DOI: $10.5430 /$ jst.v6n2p35
Accepted: May 24, 2016

URL: http://dx.doi.org/10.5430/jst.v6n2p35

\begin{abstract}
Background and aim: Mortality rates for colorectal cancer have decreased since the mid 1990s. This article provides an up-to-date report on the trends in incidence and survival of colorectal cancer in Canada. In this study we investigate the long-term trends in the incidence and relative survival ratio of colorectal cancer in Canada over the period of 1992-2008.

Patients and methods: Patients with primary colorectal cancer were selected from the Canadian Cancer Registry (CCR) dataset. Patients younger than 18 years of age were excluded. A flexible parametric model was used to estimate two- and five-year relative survival ratios and excess mortality rate.

Results: In total 159,360 patients with invasive colorectal cancer were identified of which 84,856 (53.2\%) were male, 96,495 $(60.6 \%)$ were diagnosed with colon cancer, and $62,865(39.4 \%)$ with the cancer of rectum. Mean age at diagnosis was 68.2 years $(S D=12.1)$ for men and 70.9 years $(S D=13.0)$ for women. The incidence of colorectal cancer remained almost the same for men and women in this period. Except for patients with 70 years and older, two- and five-year relative survival ratios slightly improved over time for both sexes.

Conclusion: The incidence rate of colorectal cancer remained unchanged and the two- and five-year relative survival ratios steadily increased for men and women over the study period. Although we used data up to 2008, screening programs in Canada have been implemented since 2010, therefore, incidence rates may change thereafter and advancements in treatment could further improve the survival of colorectal cancer patients.
\end{abstract}

Key Words: Relative survival, Cancer incidence, Colorectal cancer

\section{INTRODUCTION}

Colorectal cancer is recognized as the third most common cancer worldwide, and the fourth cause of global cancer deaths. ${ }^{[1,2]}$ Each year more than 1.2 million new cases are diagnosed, ${ }^{[2]}$ along with over 600,000 new deaths ${ }^{[1]}$ worldwide.
Its incidence is associated with a "Western lifestyle". ${ }^{[3]}$ In Europe, colorectal cancer is the most common cancer and the second cause of cancer death. ${ }^{[4]}$ In Canada it is the third most common cancer, and the second and third leading cause of death among male and female cancer patients, respectively. ${ }^{[5]}$

\footnotetext{
*Correspondence: Noori Akhtar-Danesh; Email: daneshn@mcmaster.ca; Address: School of Nursing, McMaster University, Hamilton, Ontario, L8S 4K1, Canada.
} 
The incidence of colorectal cancer declined dramatically between the mid-1980s to mid-1990s, only to increase through to $2000 .^{[5]}$ The Canadian Cancer Society (CCS) estimated 24,000 Canadians were diagnosed with colorectal cancer in the year 2014, representing $13 \%$ of new cancer diagnoses. ${ }^{[5]}$ Based on CCS guidelines, adults over the age of 50 and with an average risk of developing colorectal cancer are recommend a fecal occult blood test (FOBT) every 2 years. ${ }^{[5]}$ As of the year 2010, screening programs for colorectal cancer have been implemented across all Canadian provinces, in accordance with these CCS recommendations. ${ }^{[6]}$

Mortality rates for colorectal cancer have decreased since the mid-1990s. The American Cancer Society suggests that this decline is partly attributable to early finding and removal of polyps. ${ }^{[7]}$ Colonoscopy rates have increased in Canada over the last 20 years $^{[8]}$ and it would be important to assess whether this is associated with any reduction in the incidence of invasive colorectal cancer, which might suggest that polyp removal could decrease the rate of invasive colorectal cancer Also, an improvement in colorectal cancer survival may be partly attributable to early diagnosis.

In this article we examine the long-term trends in incidence and relative survival of patients diagnosed with invasive colorectal cancer in Canada between 1992 and 2008. We examine the trends in relative survival ratio and its associations with demographic variables such as age of diagnosis, sex, primary site of malignancy, and year of diagnosis.

\section{MethodS}

\subsection{Data source}

We used the colorectal cancer data from the Canadian Cancer Registry (CCR) database. The CCR is a database that includes all Canadian residents from all provinces and territories who have been diagnosed with cancer since 1992. The CCR is a collaboration among all Canadian provincial and territorial cancer registries (PTCRs) and the Health Statistics Division of Statistics Canada, where the data are maintained. The CCR records the type and number of primary cancers diagnosed for each person in Canada. The patient data is regularly linked to mortality data to optimize the accuracy of date, cause, and place of death in the CCR and to identify potential primary cancers not currently registered in the CCR. For each patient, the CCR records the individual and the tumour characteristics. ${ }^{[9]}$ Stage and size of tumour were regularly collected from 2004.

We used the International Statistical Classification of Diseases and Related Health Problems, Tenth Revision (ICD-10) to identify patients with primary invasive colorectal cancer in the CCR dataset. The ICD-10 codes include C18.x (ma- lignant neoplasm of colon), C19.x (malignant neoplasm of rectosigmoid junction), and C20.x (malignant neoplasm of rectum). We also used the International Classification of Diseases for Oncology (ICD-O-2 or ICD-O-3) to exclude all patients with in situ and non-invasive tumours from the analysis. In addition, patients were excluded if the diagnosis was based solely on autopsy or death certificate. The analysis includes patients who were 18 years of age and older at diagnosis and age at diagnosis was classified as < 50, 5059, 60-69, 70-79, and 80 and over. Data from the province of Quebec were excluded because CCR could not confirm death information. We obtained permission from the Social Sciences and Humanities Research Council of Canada for analysis and publication.

\subsection{Statistical analysis}

Using the CCR dataset and the size of the Canadian population for each sex, age group, and year of diagnosis, we calculated the age-adjusted incidence rate of invasive colorectal cancer for the period of 1992-2008. The population of Canada for each age group in 2005 were used as the standard population. We also estimated incidence rate per age group over this period and used a simple linear regression to estimate the best linear fit between incidence rate and year of diagnosis for each age group (see Figure 2).

We estimated the relative survival ratio, which is believed to be the standard and preferred index or survival for cancer registry datasets. ${ }^{[10-12]}$ It is defined as the ratio of observed survival rate between cancer patients and the expected survival rate in the general population. It is interpreted as the net survival probability in the absence of other causes where the cancer is the only cause of death. ${ }^{[13-15]}$ We estimated relative survival ratio (or simply relative survival) for patients diagnosed with colorectal cancer from 1992 to 2007 with follow-up until the end of 2008. A flexible parametric model $^{[16,17]}$ was used to estimate relative survival based on patients' sex, age group, and year of diagnosis.

In order to estimate the relative survival ratio, the Canadian population mortality rate was incorporated into the model. Canadian population size and mortality rate was retrieved from the Human Mortality Database. ${ }^{[18]}$ We also retrieved population size for the province of Quebec from the Statistics Canada website (www.statcan.gc.ca) in order to adjust the Canadian population after exclusion of Quebec data.

To estimate the relative survival ratio we fitted a model by incorporating age group, sex, cancer site (colon or rectum), year of diagnosis, and the interaction term between each two variables into a multivariable model using a forward approach. We used a likelihood ratio test to compare be- 
tween different models. Then, the two- and five-year relative survival ratio were estimated based on the final model for each age group, sex, cancer site, and year of diagnosis. The excess mortality rate ${ }^{[19]}$ was also estimated to illustrate the additional mortality in colorectal cancer patients compared to the Canadian general population.

All descriptive measures were calculated by Stata/SE 12.1 program (Stata Corporation, College Station, TX). The flexible parametric model was also fitted using stpm 2 code written for Stata program by Lambert and Royston. ${ }^{[16]}$

Table 1. Distribution of age at diagnosis and tumour site in colorectal cancer based on sex

\begin{tabular}{llll}
\hline & $\begin{array}{l}\text { Male } \\
\text { Number (\%) }\end{array}$ & $\begin{array}{l}\text { Female } \\
\text { Number (\%) }\end{array}$ & $\begin{array}{l}\text { Total } \\
\text { Number (\%) }\end{array}$ \\
\hline $\begin{array}{l}\text { Age group } \\
<50 \text { years }\end{array}$ & $6,199(7.3)$ & $5,406(7.3)$ & $11,605(7.3)$ \\
50-59 years & $13,067(15.4)$ & $9,068(12.2)$ & $22,135(13.9)$ \\
$60-69$ years & $23,131(27.3)$ & $15,549(20.9)$ & $38,680(24.3)$ \\
$70-79$ years & $27,510(32.4)$ & $23,433(31.5)$ & $50,943(32.0)$ \\
$\geq 80$ years & $14,949(17.6)$ & $21,048(28.3)$ & $35,997(22.6)$ \\
Tumour site & & & \\
Colon & $46,402(54.7)$ & $50,093(67.2)$ & $96,495(60.6)$ \\
Rectum & $38,454(45.3)$ & $24,411(32.8)$ & $62,865(39.4)$ \\
\hline Total & 84,856 & 74,504 & 159,360 \\
\hline
\end{tabular}

\section{Results}

Overall, 159,360 patients with invasive colorectal cancer were identified from the CCR dataset. Of these patients, $53.2 \%(n=84,856)$ were male and the mean age at diagnosis
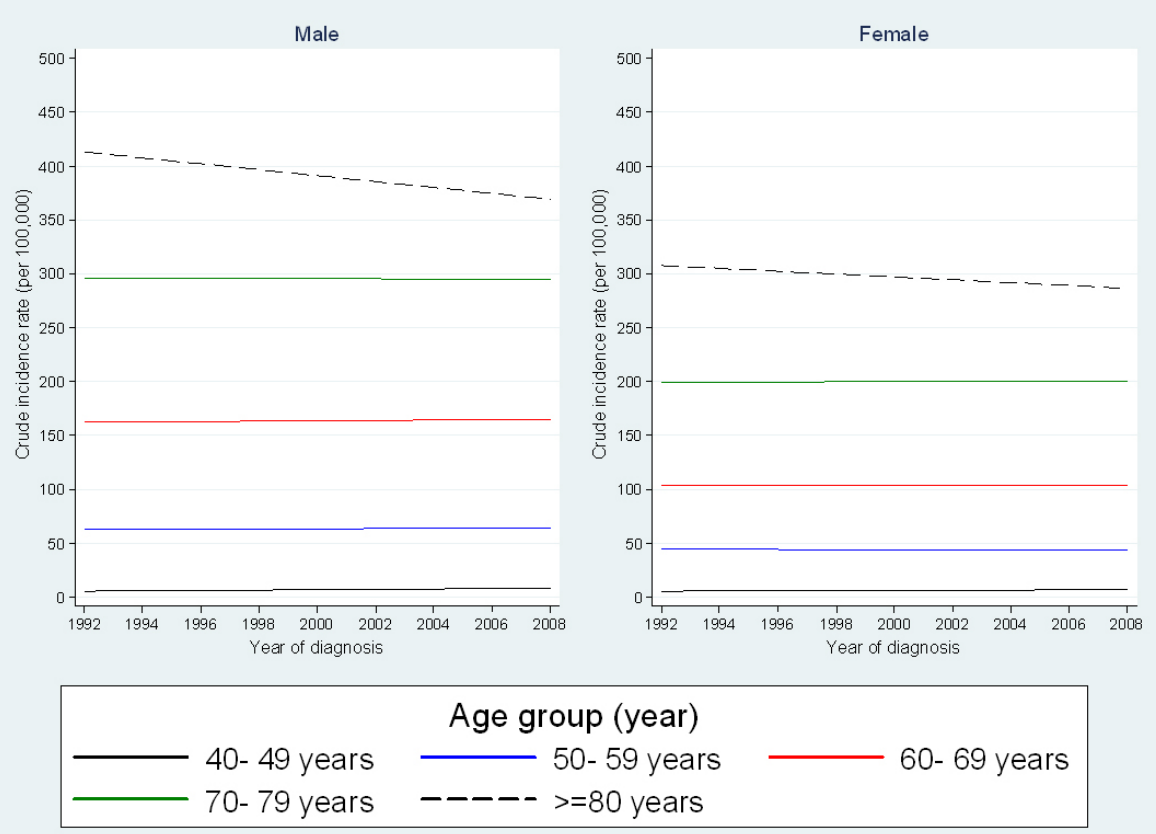

Figure 2. Trends in the incidence rate of colorectal cancer based on sex and age group in Canada 


\subsection{Incidence of colorectal cancer}

Figure 1 shows the trends in age adjusted incidence rate (per 100,000 ) in the patients over the period of 1992- 2008. Figure 2 presents the trends in incidence rate for each age group for the same period. Based on these graphs, the incidence rate for the oldest age group $(80+)$ decreased over time $(P$
$<$.001) and remained unchanged for individuals aged 50-79 years old. However, the incidence rate slightly increased, although statistically significant, for the youngest age group ( $\leq 50$ years old). This increase was observed in both men and women over the period of 1992-2008 $(P<.001)$.

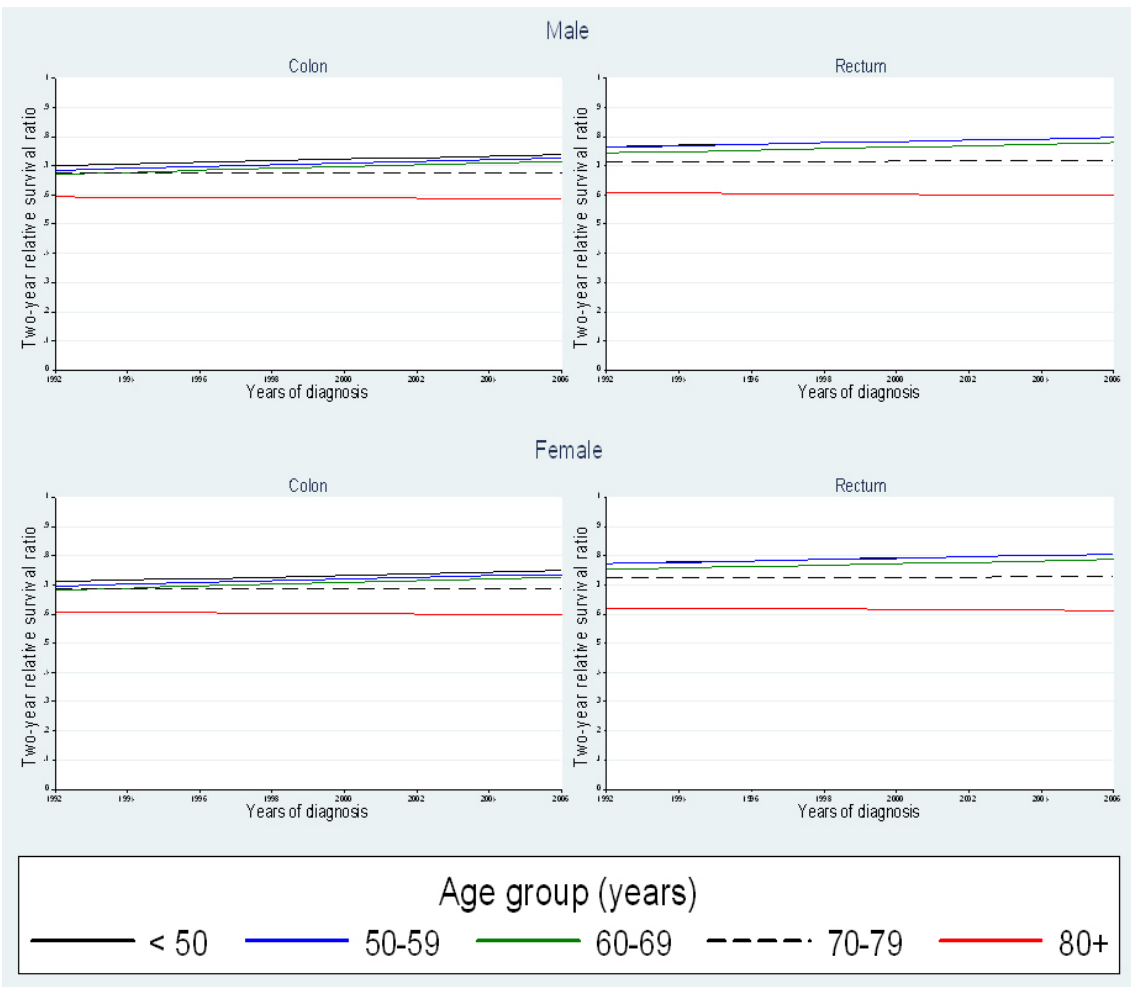

Figure 3. Two-year relative survival ratio for colorectal cancer based on sex, age group, and year of diagnosis

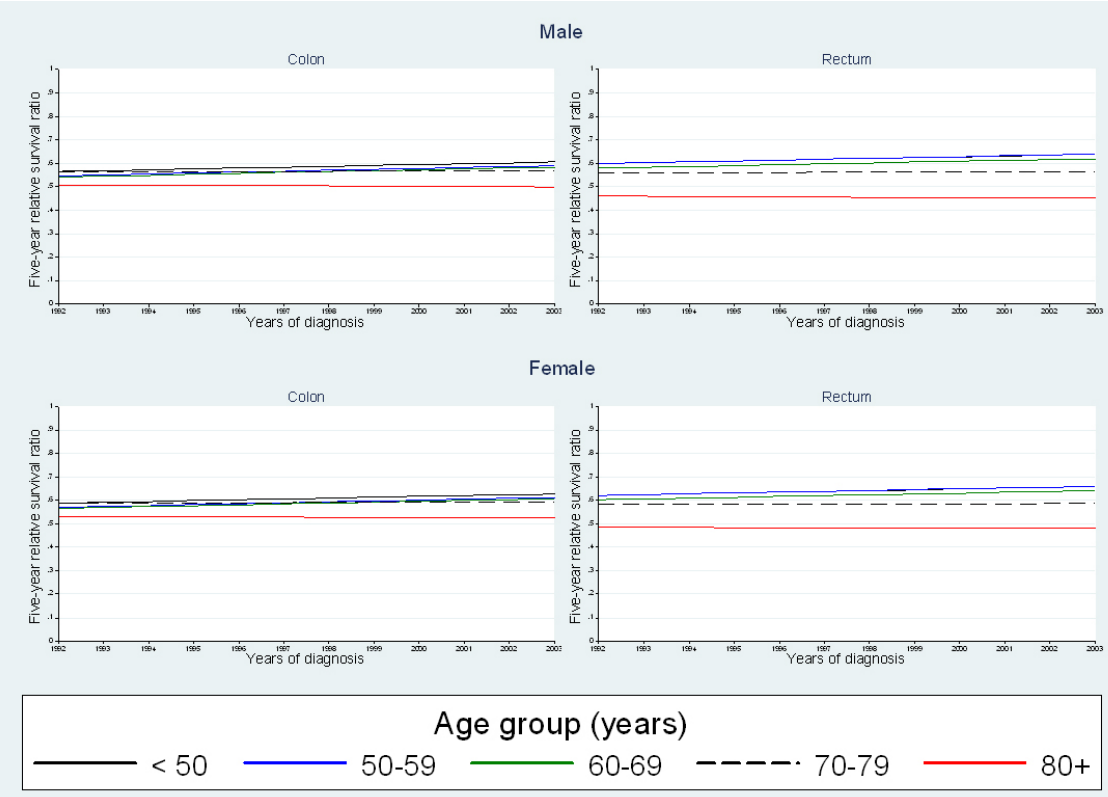

Figure 4. Five-year relative survival ratio for colorectal cancer based on sex, age group, and year of diagnosis 


\subsection{Trends on relative survival and excess mortality rate}

The final model from fitting a flexible parametric model included sex, age group, site of tumour, year of diagnosis, the interaction between age group and site, and the interaction term between age group and year of diagnosis. Also based on the log-likelihood ratio test, sex, age group, and site of tumour were included as time dependent variables in the model. We presented the results as the trends in two- and five-year relative survival ratios based on age group, sex, tumour site, and year of diagnosis in Figures 3 and 4. Twoand five-year relative survivals slightly increased over time for patients younger than 70 years for both tumor sites and for both males and females. However, it remained almost constant for all patients with 70 years and older $(P<.001)$.

The trends in excess mortality rate because of invasive colon and rectal cancers are shown in Figure 5. For both cancers, the highest excess mortality rate is observed just after diagnosis, then decreased over time. However, excess mortality rate is higher in men and for colon cancer patients. This rate remains substantially larger in older patients, up to two years after diagnosis for colon cancer, and three years for rectal cancer patients.

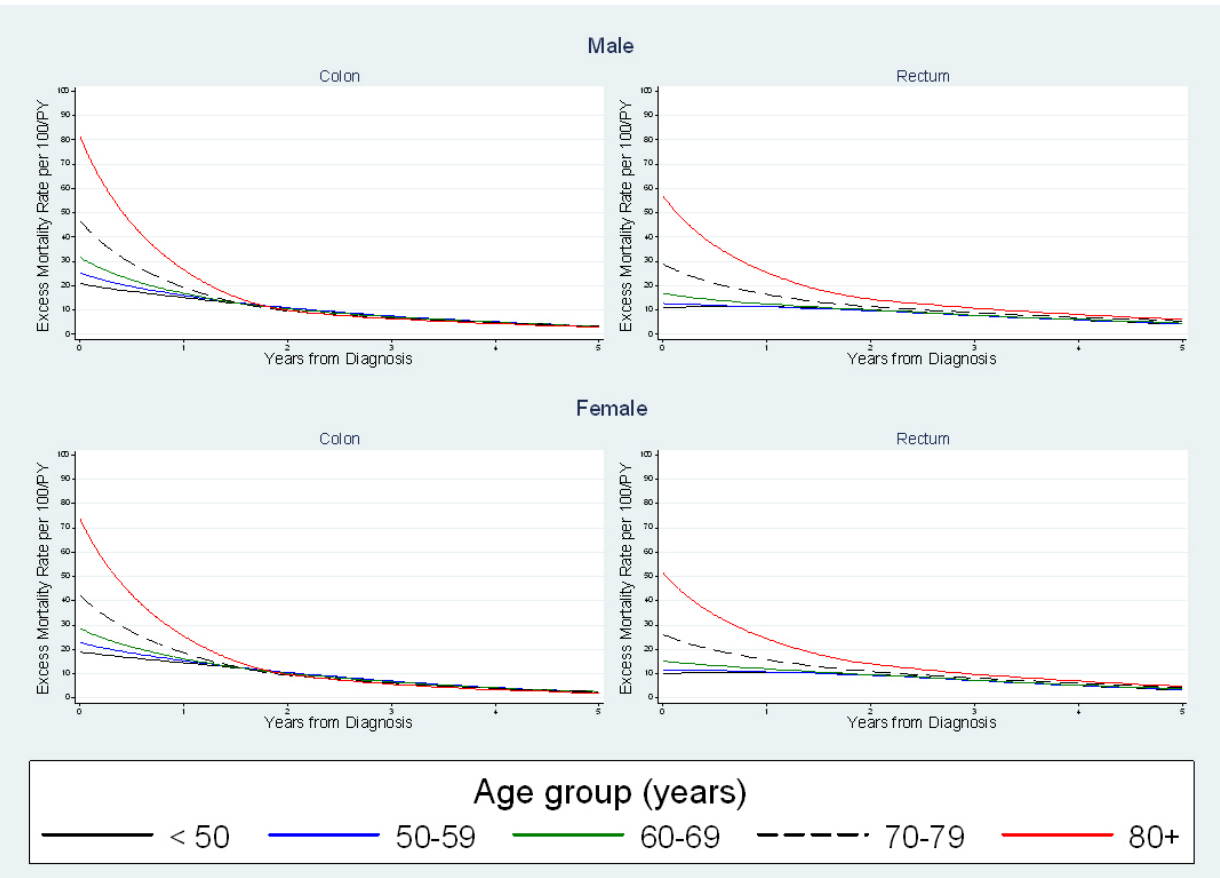

Figure 5. Five-year trends in excess mortality rate due to colorectal cancer based on sex and age group

\section{Discussion}

The main findings of this study are: 1) overall incidence rates for colorectal cancer remained unchanged from 1992 to 2008 , although a slight increase was noted in the youngest age group; 2) incidence and mortality rates were lower in females; 3) the site distribution of cancer varied between men and women, with rectal cancer being more common in men while colon cancer was more common in women; 4) 2- and 5-year relative survival ratios increased for patients younger than 70 years old between 1992-2007, an effect that was more pronounced in younger patients; and 5) excess mortality rate was highest shortly after diagnosis and higher in men and for colon cancer patients.

The incidence rates of colorectal cancer are 65 and 54 per 100,000 for male and female patients, respectively. However, it is noteworthy that the direction of the trend in incidence varies between age groups. Although incidence slightly increased in the youngest age group, it decreased for the oldest age group. These findings are in contrast to an earlier Canadian study, which reported an overall decreasing trend in the incidence of colorectal cancer. ${ }^{[20]}$ It is important to note that the aforementioned study focused on a different time span (1981-2001), which may account for the observed differences. Similarly, a study from the Netherlands reported an increasing incidence of colorectal cancer for both men and women. ${ }^{[21]}$ This increased incidence was in agreement with other European data, and the authors suggest that changes in risk factors such as diet and lifestyle may account for the rising incidence. ${ }^{[21]}$

The lower incidence rate of colorectal cancer and the relative survival benefit in women has been replicated across numerous other studies. ${ }^{[20-22]}$ Another Canadian study by Gao et 
$a l .{ }^{[20]}$ reported that both incidence and mortality rates for colorectal cancer were considerably higher in men. However, this trend was not replicated in older age groups, in which women outnumber men. ${ }^{[20]}$ Similar trends have also been observed in studies from Germany and the Netherlands. ${ }^{[21,22]}$ It has been suggested that the decreased risk of colorectal cancer in women is attributable to female sex hormones. ${ }^{[22]}$ Both endogenous and exogenous hormones (including oral contraceptives and hormone replacement therapy) confer protective effects against colorectal cancer. ${ }^{[22]}$ In addition, hormone replacement therapy may extend survival in colorectal cancer patients. ${ }^{[22]}$ It is hypothesized that these effects are due to the immune-modulating effects of sex hormones. In particular, testosterone has inhibitory effects on the immune system, while female sex hormones stimulate immunity. ${ }^{[23]}$

The site distribution of colorectal cancer between female and male patients was also a finding of interest. The present analysis found more cases of rectal cancer among men, while colon cancer was more prevalent among women. These findings are consistent with the current literature. ${ }^{[20,22]}$ It has been suggested that these differences in CRC site should be considered in the implementation of screening programs, as sigmoidoscopy may be more appropriate than colonoscopy in certain populations. ${ }^{[24]}$

In terms of survival, we found that for patients diagnosed between 1992 and 2007, the 2- and 5-year relative survival slightly increased for patients younger than 70 years old, and the increase was more pronounced in younger patients. The trend of increasing relative survival for colon cancer has been documented in numerous other studies from Canada, U.S., and Europe. ${ }^{[21,25-27]}$ An earlier Canadian study reported an increase in survival rates between 1979-1991, attributing such improvement to earlier diagnosis and better management. ${ }^{[27]}$ This study supports these findings and this may relate to earlier diagnosis as more colonoscopies are being conducted in Canada, which may preclude the occurrence of invasive colorectal cancer. Presumably, this increase in relative survival has become even more pronounced since the introduction of screening programs across the country in 2010 .

Figure 5 depicts the trends in excess mortality over time. The magnitude of the excess mortality rate highly depends on the age of patients and time from diagnosis. Also, its maximum is at the time of diagnosis and sharply decreases thereafter for the older age groups ( $\geq 70$ years). This suggests that older colorectal cancer patients die shortly after diagnosis. This higher excess mortality rate for the older age groups is paralleled with a lower relative survival for these age groups. This phenomenon can be due to age, co-morbidities, or under- treatment for these age groups. ${ }^{[25,28]}$ Based on a systematic review, Bouchardy et al. ${ }^{[29]}$ identified numerous factors potentially resulting in under-treatment. These factors include physicians' preferences ${ }^{[30,31]}$ of less aggressive therapy for older patients ${ }^{[29]}$ and suboptimal management of the adverse effects of chemotherapy, pain management, palliative care, and reconstructive surgery. ${ }^{[29]}$ Finally, excess mortality rate was found to be higher for colon cancer and male patients. A European study also found excess mortality to be higher in colon cancer and older patients, up to three months after the initial diagnosis. ${ }^{[32]}$

In this work we used a high quality population-based dataset for analysis that was collected over the period of 1992-2008 and reported trends in incidence, two- and five-year relative survival, which provides more insight to the incidence and survival of patients with colorectal cancer. Also, the use of a flexible parametric model for analysis allowed for a more powerful approach compared to the other techniques in resembling the actual patterns in mortality and survival. ${ }^{[15,33]}$

As a limitation, we did not use the tumour stage in this analysis because the dataset did not include such information. This, however, merits a thorough examination in itself and can be the focus of a future article. Another limitation is that we did not have access to CCR dataset beyond the year 2008. The CCR has not yet released its publicly available dataset beyond this point; therefore, this analysis provides the most up-to-date report on the incidence and survival of colorectal cancer in Canada. Finally, treatment strategies were not accounted for in this analysis. It is possible that the improved in survival in younger patients could be due to more aggressive treatment; however, we are unable to confirm such a hypothesis. Furthermore, stage of cancer at diagnosis was not included, and it would be important to investigate the impact of different treatment modalities based on stage of disease.

In conclusion, this study found that the overall Canadian incidence in colorectal cancer remained unchanged between the years 1992-2008. Female patients appeared to have both a lower incidence and a longer survival advantage. Furthermore, excess mortality rate was highest shortly after diagnosis and 2- and 5-year relative survival ratios showed an upward trend over time. Although this study captured data between 1992 and 2008, screening programs in Canada have been implemented in all provinces as of the year 2010 and the Canadian Partnership Against Cancer reported a variability in screening rates across the country, ranging from $28.3 \%$ in Quebec to 59.2\% in Manitoba. ${ }^{[34]}$ Therefore, incidence and survival rates may considerably change after 2010 and advancements in treatment will hopefully improve the survival 
of colorectal cancer patients in Canada.

\section{ACKNOWLEDGements}

We are thankful to the Canadian Cancer Registry and Statistics Canada for access to the CCR dataset, although the interpretation and reporting of these data are the sole respon- sibility of the authors. We are also thankful to the staff of the Research Data Centre for their help.

\section{CONFLicts OF InTEREST Disclosure}

We declare no conflict of interest.

\section{REFERENCES}

[1] Jemal A, Siegel R, Ward E, et al. Cancer statistics. CA Cancer J Clin. 2009; 59: 225-49. PMid:19474385. http://dx.doi.org/10.33 22/caac. 20006

[2] Ferlay J, Soerjomataram I, Dikshit R, et al. Cancer incidence and mortality worldwide: sources, methods and major patterns in GLOBOCAN 2012. Int J Cancer. 2014. PMid:25220842.

[3] Brenner H, Kloor M, Pox CP. Colorectal cancer. Lancet. 2014; 383 : 1490-502. http://dx.doi.org/10.1016/S0140-6736(13) 616 49-9

[4] Ferlay J, Parkin DM, Steliarova-Foucher E. Estimates of cancer incidence and mortality in Europe in 2008. Eur J Cancer. 2010; 46: 765-81. PMid:20116997. http://dx.doi.org/10.1016/j.ejc a. 2009.12.014

[5] Canadian Cancer Society's Advisory Committee on Cancer Statatistics: Canadian Cancer Statistics 2014. Toronto, ON. 2014.

[6] Canadian Partnership Against Cancer: The 2010 Cancer System Performance Report. Toronto, ON. 2010.

[7] American Cancer Society: Colorectal Cancer. Atlanta, New Jersey. 2014.

[8] Rabeneck L, Paszat LF, Saskin R, et al. Association between colonoscopy rates and colorectal cancer mortality. Am J Gastroenterol. 2010; 105: 1627-32. PMid:20197758. http://dx.doi.org /10.1038/ajg.2010.83

[9] Statistics Canada: Canadian Cancer Registry (http: //www23.statcan.gc.ca/imdb/p2SV.pl?Function=ge tSurvey\&SDDS=3207, retrieved Dec. 11, 2014). Ottawa, Canada. 2012.

[10] Canadian Cancer Society's Steering Committee on Cancer Statistics: Canadian Cancer Statistics 2011. Toronto. 2011.

[11] Dickman PW, Sloggett A, Hills M, et al. Regression models for relative survival. Stat Med. 2004; 23: 51-64. PMid:14695639. http://dx.doi.org/10.1002/sim.1597

[12] Dickman PW, Adami HO. Interpreting trends in cancer patient survival. J Intern Med. 2006; 260: 103-17. PMid:16882274. http: //dx.doi.org/10.1111/j.1365-2796.2006.01677.x

[13] Ederer F, Axtell LM, Cutler SJ. The relative survival tart: a statistical methodology. National Cancer Institute Monograph. 1961; 6: 101-2. PMid:13889176.

[14] Pokhrel A, Hakulinen T. How to interpret the relative survival ratios of cancer patients. Eur J Cancer. 2008; 44: 2661-7. PMid:18819791. http://dx.doi.org/10.1016/j.ejca.2008.08.016

[15] Rutherford MJ, Dickman PW, Lambert PC. Comparison of methods for calculating relative survival in population-based studies. Cancer Epidemiol. 2012; 36: 16-21. PMid:21840284. http://dx.doi.o $\mathrm{rg} / 10.1016 / \mathrm{j}$. canep. 2011.05.010

[16] Lambert PC, Royston P. Further development of flexible parametric models for survival analysis. The Stata Journal. 2009; 9: 265-90.

[17] Royston P, Parmar MK. Flexible parametric proportional-hazards and proportional-odds models for censored survival data, with application to prognostic modelling and estimation of treatment effects. Stat Med. 2002; 21: 2175-97. PMid:12210632. http://dx.doi.org/10.10 $02 / \operatorname{sim} .1203$

[18] Human Mortality Database. University of California, Berkeley (USA), and Max Planck Institute for Demographic Research (Germany). Available at www.mortality. orgorwww . humanmortalit y. de (data downloaded on 20/02/2014).

[19] Suissa S. Relative excess risk: an alternative measure of comparative risk. Am J Epidemiol. 1999; 150: 279-82. PMid:10430232. http: //dx.doi.org/10.1093/oxfordjournals.aje.a009999

[20] Gao RN, Neutel CI, Wai E. Gender differences in colorectal cancer incidence, mortality, hospitalizations and surgical procedures in Canada. J Public Health (Oxf). 2008; 30: 194-201. PMid:18445612. http://dx.doi.org/10.1093/pubmed/fdn019

[21] Lemmens V, van SL, Janssen-Heijnen M, et al. Trends in colorectal cancer in the south of the Netherlands 1975-2007: rectal cancer survival levels with colon cancer survival. Acta Oncol. 2010; 49: 784-96. PMid:20429731. http://dx.doi.org/10.3109/02841 861003733713

[22] Majek O, Gondos A, Jansen L, et al. Sex differences in colorectal cancer survival: population-based analysis of 164,996 colorectal cancer patients in Germany. PLoS One. 2013; 8: e68077. PMid:23861851. http://dx.doi.org/10.1371/journal . pone. 0068077

[23] Wichmann MW, Muller C, Hornung HM, et al. Gender differences in long-term survival of patients with colorectal cancer. Br J Surg. 2001; 88: 1092-8. PMid:11488795. http://dx.doi.org/10.10 46/j.0007-1323.2001.01819.x

[24] Brenner H, Hoffmeister M, Arndt V, et al. Gender differences in colorectal cancer: implications for age at initiation of screening. Br J Cancer. 2007; 96: 828-31. PMid:17311019. http://dx.doi.org $/ 10.1038 /$ sj.bjc. 6603628

[25] Brenner H, Bouvier AM, Foschi R, et al. Progress in colorectal cancer survival in Europe from the late 1980s to the early 21 st century: the EUROCARE study. Int J Cancer. 2012; 131: 1649-58. PMid:21607946. http://dx.doi.org/10.1002/ijc. 26192

[26] Rutter CM, Johnson EA, Feuer EJ, et al. Secular trends in colon and rectal cancer relative survival. J Natl Cancer Inst. 2013; 105: 1806-13. PMid:24174654. http://dx.doi.org/10.1093/jnci/djt299

[27] Ugnat AM, Xie L, Semenciw R, et al. Survival patterns for the top four cancers in Canada: the effects of age, region and period. Eur J Cancer Prev. 2005; 14: 91-100. PMid:15785312. http: //dx.doi.org/10.1097/00008469-200504000-00004

[28] Akhtar-Danesh N, Lytwyn A, Elit L. Five-year trends in mortality indices among gynecological cancer patients in Canada. Gynecol Oncol. 2012; 127: 620-4. PMid:22943877. http://dx.doi.org/1 $0.1016 / j \cdot$ ygyno.2012.08.038

[29] Bouchardy C, Rapiti E, Blagojevic S, et al. Older female cancer patients: importance, causes, and consequences of undertreatment. J Clin Oncol. 2007; 25: 1858-69. PMid:17488984. http: //dx.doi.org/10.1200/JC0.2006.10.4208 
[30] Mandelblatt JS, Hadley J, Kerner JF, et al. Patterns of breast carcinoma treatment in older women: patient preference and clinical and physical influences. Cancer. 2000; 89: 56173. http://dx.doi.org/10.1002/1097-0142(20000801)89: 3<561: : AID-CNCR11>3.0.CO; $2-\mathrm{A}$

[31] Silliman RA, Troyan SL, Guadagnoli E, et al. The impact of age, marital status, and physician-patient interactions on the care of older women with breast carcinoma. Cancer. 1997; 80: 132634. http://dx.doi.org/10.1002/(SICI) 1097-0142(199710 01) $80: 7<1326::$ AID-CNCR20>3.0.CO;2-8
[32] Morris EJ, Sandin F, Lambert PC, et al. A population-based comparison of the survival of patients with colorectal cancer in England, Norway and Sweden between 1996 and 2004. Gut. 2011; 60: 108793. PMid:21303917. http://dx.doi.org/10.1136/gut. 2010. 229575

[33] Dickman PW, Lambert PC, Coviello E, et al. Estimating net survival in population-based cancer studies. Int J Cancer. 2013; 133: 519-21. PMid:23338817. http://dx.doi.org/10.1002/ijc. 28041

[34] Canadian Partnership Against Cancer: The 2014 Cancer System Performance Report. Toronto, ON. 2014. 